\title{
Diminution of Weight and Heat Accumulation in Transfemoral Socket Using PE/MWCNT Composite
}

\author{
Broster Maria Viswasam $(\mathbb{D}$ and Anderson Arul Gnana Dhas $\mathbb{D}$ \\ School of Mechanical Engineering, Sathyabama Institute of Science and Technology, Chennai 600119, India \\ Correspondence should be addressed to Broster Maria Viswasam; broster1987@gmail.com
}

Received 18 February 2020; Revised 4 May 2020; Accepted 13 May 2020; Published 5 June 2020

Academic Editor: Pierre Verge

Copyright (C) 2020 Broster Maria Viswasam and Anderson Arul Gnana Dhas. This is an open access article distributed under the Creative Commons Attribution License, which permits unrestricted use, distribution, and reproduction in any medium, provided the original work is properly cited.

\begin{abstract}
The socket plays an important role in prostheses by providing structural integrity and suspension to the distal thigh of an amputee. Heat accumulation and weight of the socket increase the energy consumption in the amputee. To overcome the same, widely used polyester-based sandwich-structured composite was reinforced with $0.2,0.4,0.6,0.8$, and $1 \mathrm{wt} \%$ multiwalled carbon nanotube (MWCNT) and analyzed for the thermal and mechanical properties. MWCNT added in a small weight proportion with polyester enhances the mechanical properties of the resulting nanocomposites as they have excellent mechanical and physical properties. The flexural and thermal property was evaluated as per ASTM D790 and ISO 22007-2 standard. It was noticed that the thermal property enhances with increase in wt $\%$ of MWCNT and mechanical properties decreased when more than $0.6 \mathrm{wt} \%$ MWCNT was reinforced. Hence, the sandwich-structured composite was prepared using polyester resin, 2 to 10 stockinette layers, fiberglass cloth, and $0.6 \mathrm{wt} \%$ of MWCNT. The thermal conductivity and flexural strength of $0.6 \mathrm{wt} \%$ MWCNT-reinforced sandwich-structured composite were enhanced upto $68.4 \%$ and $11.4 \%$ for $2-10$ stockinette layers, respectively, while comparing to the unreinforced polyester sandwich-structured composite. The $0.6 \mathrm{wt} \% \mathrm{MWCNT}$-reinforced sandwich-structured composite may help in reducing the weight and heat build up in the socket. Hence, it is recommended to analyze further on their application in transfemoral socket preparation to bring down an amputee's metabolic cost.
\end{abstract}

\section{Introduction}

Amputation in the lower limb is one of the most traumatic happenings in a person's life. Human lower limb is one of the crucial parts, which takes care of the necessary movement function for our day-to-day activities. In addition to the loss of functionality, economic, social, and psychological life of the amputee faces immense consequences, [1]. The lower limbs have very complex structure and are highly articulated to accomplish versatile and sophisticated joint movements. Transfemoral amputation is a surgical measure to sever the lower limb above the knee joint. Based on world disability statistics $2010,10 \%$ of the world population has some form of disability. As per Census India 2011, among the disabled people, $20 \%$ suffers from locomotive disability where male and female represent about $22 \%$ and $18 \%$, respectively. In the locomotive disability, $18.5 \%$ of people with limb loss are transfemoral amputees. As of 2005, 1.6 million people in the US are suffering from limb loss, and by 2050, it is predicted to be 3.6 million people [2].

After the amputation, prosthesis is widely used to carry out the daily activities. A transfemoral prosthesis consists of socket, knee, foot, and shin components. Transfemoral socket is an intermediate part between the residual stump and prosthetic knee joint. The performance of prosthesis is highly depended on the socket system, and poor performance of the same will lead to discomfort and severe pain in amputees. The load in the socket during gait affects the soft tissue and may result in various skin issues including abrasions, callosits, cysts, edema skin irritation, and blisters [1]. These skin issues will increase the metabolic cost [3]. An inflexible socket will cause discomfort and may lead the way to nerve injury and constant swelling [4]. The sockets used nowadays reduce the heat transfer rate as they inadvertently turn into an insulating barrier [5]. If the heat transfer rate in the socket is less, perspiration stays in the hair follicles and lead to 
bacterial invasion and skin maceration [4]. As the heat accumulation increases due to less heat transfer, the skin temperature increases, where $1^{\circ} \mathrm{C}$ rise in the skin temperature will lead to $10 \%$ increase in metabolic cost [6]. Several investigators have demonstrated that the increase in prosthetic weight results in increased metabolic cost [7]. The energy consumption of an amputee can be minimized up to $56 \%$ by using light weight socket with increased heat transfer rate [8]. The existing socket material is heavy and has poor heat transfer rate, which is a huge concern for the amputee. The transfemoral socket material is made up of thermoplastic or thermosetting materials. Thermoset materials such as acrylic, epoxy, and polyester are used for prosthetic socket. Many studies were carried out to decide the manufacturing techniques and criteria for knitting aramid, glass fiber, and carbon fiber into stockinette materials suitable for lamination in prosthetic laboratories [6]. From detailed literature studies, it was noticed that polyester resin is chosen in most cases for its low viscosity, rapid cure time, and low cost compared to any other thermoset polymer [9]. The mechanical and thermal properties of polyester resin can be further increased by reinforcing them with nanoparticles [10].

The present pioneer research in future engineering applications field is the development of nanoparticle-reinforced polymer composites [11-15]. Carbon nanotubes (CNTs) are unique materials with superior electrical, mechanical, and thermal properties [10]. The reinforcement of nanoparticles will result in the required properties of the polymer [16]. Among all the fillers, a lot of attention is being paid for MWCNT, as they possess superior properties compared to other fillers [17]. CNTs have excellent tensile strength, high Young's modulus, and superlative thermal and electrical properties and as a result attract the attention of many researchers [18]. Mechanical properties of polymer composites can be enhanced by increasing MWCNTs-matrix interfacial bond $[9,19,20]$. The matrix interfacial bond is one of the most important aspects concerning the shear stress transfer to the reinforcement structure [21, 22]. The mechanical properties of MWCNT can be enhanced further by proper chemical treatment. Etika et al. and Seyhan et al. [23, 24] added untreated, $\mathrm{NH}_{2}$ and $\mathrm{COOH}$ attached MWCNT with epoxy resin and observed that the polymer composite with $0.3 \mathrm{wt} \% \mathrm{COOH}$ attached MWCNT provides enhanced tensile strength of $73 \%$ as compared to the neat epoxy resin. The carbon fiber-reinforced polymer (CFRP) specimens were produced by reinforcing multiwalled carbon nanotubes functionalized with carboxylic acid (COOH-MWCNT) and epoxy nanocomposite matrix. The experimental result shows that adding $1.5,1.0$, and $0.1 \mathrm{wt} \%$ MWCNT, the interlaminar fracture toughness of the CFRP composite was enhanced upto $17 \%, 20 \%$, and 25\%. Borowski et al. and Zhou et al. $[25,26]$ observed that the COOH-functionalized MWCNT has increased degree of curing compared to nonfunctionalized MWCNTs with diglycidyl ether.

Arun and Kanagaraj [27] optimized the processing condition of $\mathrm{COOH}$ bonded in epoxy MWCNTs matrix based on mechanical properties and thermal conductivity. It was observed that the solvent dispersion technique along with vacuum oven evaporation method significantly improves the mechanical properties of polymer nanocomposites. Hoang and Yum [28] reinforced $0.1 \mathrm{wt} \%$ of MWCNT with polyester composite, and the results show $8.64 \%$ intensification in the tensile strength and $14.58 \%$ intensification in Young's modulus. Vahedi et al. [29] observed that reinforcing $0.05 \mathrm{wt} \%$ of MWCNT with polyester results in the increase of flexural strength and flexural modulus by $45.1 \%$, $13.79 \%$, respectively, compared to the unreinforced polyester. Shokrieh et al. [30] reinforced different wt $\%$ of MWCNT with polyester and observed that $0.05 \mathrm{wt} \%$ MWCNT exhibit $6 \%$ and $20 \%$ enhancement in tensile and flexural strengths, respectively. Another study of Makki et al. [18] shows that the reinforcement of $0.3 \mathrm{wt} \%$ of MWCNTs with polyester increases the tensile strength, strain, and Young's modulus by $4.2 \%, 86.0 \%$, and $27.9 \%$, respectively. The MWCNT has high thermal conductivity of $3000 \mathrm{~W} / \mathrm{mK}$, and huge surface area $[31,32]$, thermal conductivity, and surface area play a vital role for the conductive heat transfer. Beg et al. [16] observed that comparing to the unreinforced polyester, the thermal conductivity of polyester composite reinforced with $10 \mathrm{wt} \%$ MWCNT increases by $30 \%$. Zhou et al. [26] observed that adding $0.6 \mathrm{wt} \%$ of MWCNT with epoxy matrix enhances the thermal conductivity by 20.7 times with respect to the thermal conductivity of pure epoxy. Park et al. [33] also confirmed that the reinforcement of MWCNT in the epoxy matrix enhances the heat conduction of the composite.

Though different research works are going on in the field of polyester-based nanocomposites, it was noticed that the MWCNT filler concentration in polyester which optimizes the mechanical and thermal conductivity is not reported. Moreover, the root causes for the improvement or deterioration of mechanical properties of polyester composite when reinforced with MWCNT were not analyzed exhaustively. Hence, the optimization of the proper weight fraction of MWCNT/polyester resin with respect mechanical properties and thermal properties was attempted. Also, no study has been ever undertaken to optimize the concentration of MWCNTs in polyester sandwich-structured composite. Thus, to minimize the energy cost of walking for an amputee, optimization of MWCNT reinforced in polymer sandwichstructured composite was attempted to enhance the mechanical and thermal properties of socket material.

\section{Materials and Methods}

2.1. Materials. MWCNT was acquired from Minako Corporation, Madhya Pradesh, India, with specification as follows: outer diameter $12-15 \mathrm{~nm}$, purity $97 \mathrm{wt} \%$, length 3-10 $\mu \mathrm{m}$, ash content $<2 \mathrm{wt} \%$, and specific surface area $>250-270 \mathrm{~m}^{2} / \mathrm{g}$. The thermosetting polymer matrix is a preaccelerated, antisagging, nonwaxed quick curing isophthalic unsaturated polyester resin (PR), Methyl Ethyl Ketone Peroxide (MEKP) hardener supplied by M/s. Ajanta enterprises Chennai. Polyester resin appears clear with viscosity of 1.95 poise, cure time of $2 \mathrm{hr}$ at $800^{\circ} \mathrm{C}$, and hardener having density of $0.94 \mathrm{~g} / \mathrm{ml}$. Also, fiberglass cloth made of S-glass and stockinette were also purchased from M/s. Fakrudeen Corporation, Chennai, India. 
2.2. Composite Fabrication. The resin was mixed with MEKP hardener in the weight ratio of 1:0.4 using a mechanical stirrer for about 20 mins, and the resultant compound was decanted into the die. Pure polyester specimen was attained once the composite was cured at $78 \pm 2^{\circ} \mathrm{C}$ for about $2 \mathrm{~h}$ in a hot air oven (BST/HAO-1122) chamber with digital temperature controller. As per the suggestion by Park et al. [34], polyester composite was prepared by mixing $0.2,0.4,0.6$, 0.8 , and $1 \mathrm{wt} \%$ of MWCNT. In case of composite preparation, the polyester resin was liquefied in acetone for $45 \mathrm{mins}$ with a bath sonicator in $20 \mathrm{kHz}$ frequency (BandelinSonorex Digital 10P, $352 \mathrm{kHz}, 500 \mathrm{~W}$ ) and with the help of a tip sonicator (Hielscher UP400S, Tetlow, Germany). MWCNT was dissolved in acetone at $45 \mathrm{kHz}$. The temperature during the mixture was sustained to less than $30^{\circ} \mathrm{C}$ with the help of an ice bath. Later, the mixture was bath sonicated for 45 more mins. After bath sonication, the mixture was vacuum dried in room temperature to remove acetone. Later, hardener in required quantity was added to the polyester-MWCNT mixture by hand mixing of about 15 mins and transferred to the mold. Thus, the composite samples were prepared.

\subsection{Sandwich-Structured Fabrication. Sandwich-structured} composite was made by layering stockinette (2 to 10 layers), fiberglass cloth, and polyester resin, and the sandwichstructured composite was reinforced with $0.6 \mathrm{wt} \%$ MWCNT. The sandwich-structured composite mold area made up of $200 \times 200 \mathrm{~mm}$, and hand layup technique was used to prepare the sandwich-structured composite. A release liquid was spritzed on top of the mold so that the polymer would not stick to the surface of the mold. A perforated film sheet is placed on the top and bottom layer of the sandwichstructured composite to obtain the smooth surface [35]. A single layer of stockinette was placed on top of the perforated film and the polyester resin mixed with hardener was poured above the stockinette layers [36]. Fiberglass cloth was layered on top, and polyester resin mixture was poured above the fiberglass cloth. Another layer of stockinette was placed on top of this and a required amount of polyester resin mixture was poured. The set of layers was repeated again till we get the desired number of sandwich-structured composite $(2,4$, $6,8,10)$. Finally, the composite was cured for $4 \mathrm{hr}$ in room temperature to get the sandwich-structured composite.

2.4. Characterization. The weight percentage was measured in electric weighing machine (AT-266-2: Electronic Balance). The three-point bending test was taken using an INSTRON 5544 universal testing machine, and the required test specimens were cut by using abrasive water jet machining set-up as per ASTM D790 standard. Six specimens per test condition were carried out to confirm the repeatability of the test results. The cross-head speed of $1 \mathrm{~mm} / \mathrm{min}$ was used for the flexural tests [37]. The surface of MWCNT was studied using a $200 \mathrm{KV}$, a ZEISS model upright optical microscope (Axiotech with halogen lamp, 100x) to confirm the voids in polyester composites. The differential scanning calorimeter (Pyris 6 , DSC) using a heating rate of $30^{\circ} \mathrm{C}$ per minute from room temperature to $400^{\circ} \mathrm{C}$ with polyester/MWCNT was carried out to determine the glass transition temperature, $T_{\mathrm{g}}$ [38].

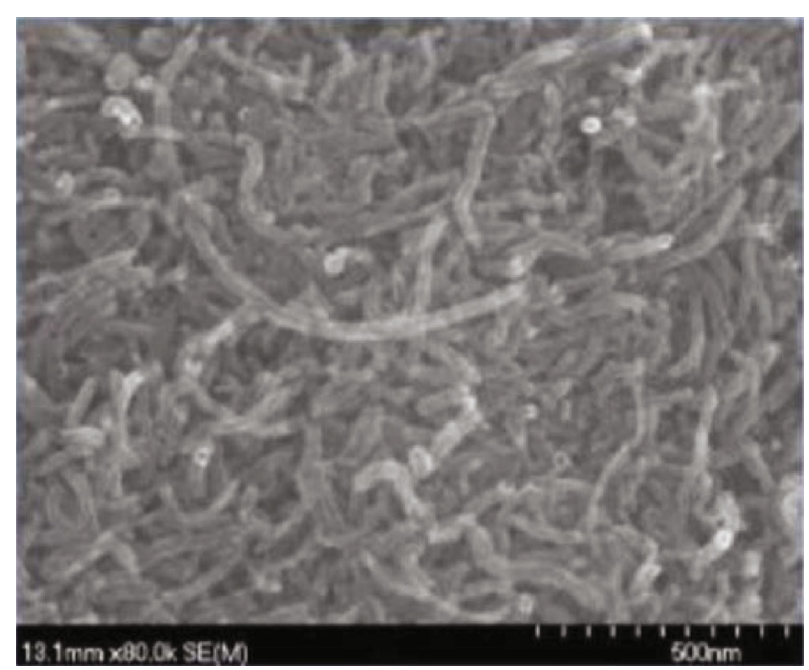

Figure 1: SEM image of MWCNT.

The relative crystallinity of the composite sample was measured using the ratio of the summation of scattering of the crystalline phases to the total scattering. Sample was measured by bar samples; the same thickness was used for Xray diffraction (XRD) measurements. Studies were performed by an X-ray diffractometer (XRD. JDX-3530M, JEOL, Japan). The polyester/MWCNT composite's electrical conductivity was taken using the Keithley 617 Programmable electrometer as a source power of stabilized DC power. The direct current (DC) conductivity of the composites was determined based on the frequency dependency of the AC conductivity in the region of low-frequency plateau [39]. The viscosity of polyester/MWCNT mixture was tested in a Rheometer, Make: M/S Anton parr, Model: Physica MCR 101 to study the impact of MWCNT reinforcement on the viscosity of polyester. The polyester/MWCNT composite's thermophysical properties were measured in accordance with ISO 22007-2 standard and a MODEL: 2200; HOT DISK was used for the measurement. The MWCNT was visualized using field emission scanning electron microscope (SEM, SUPRA 55-CARL ZEISS, GERMANY).

\section{Results and Discussion}

3.1. Mechanical Properties of Polyester Nanocomposite. The SEM image, shown in Figure 1, does not show any severe defects on the surface of the bought out MWCNT. MWCNT possess excellent electrical, mechanical, thermal properties, low density, high strength, high toughness, high surface area, good flexibility, and high chemical stability [40]. Good dispersion of functionalized MWCNTs into the matrix could enhance the properties of the polymeric nanocomposites. Chemical functionalization of the nanocomposites prepared with MWCNT-COOH oxidation shows increase in flexural behaviour [41]. The flexural load vs. displacement plots obtained for test samples of unreinforced polyester and 0.2 , $0.4,0.6,0.8$, and $1 \mathrm{wt} \%$ of COOH-MWCNT reinforced polyester is shown in Figure 2. It was observed that the flexural load was enhanced up to $0.6 \mathrm{wt} \%$ of MWCNT and beyond 


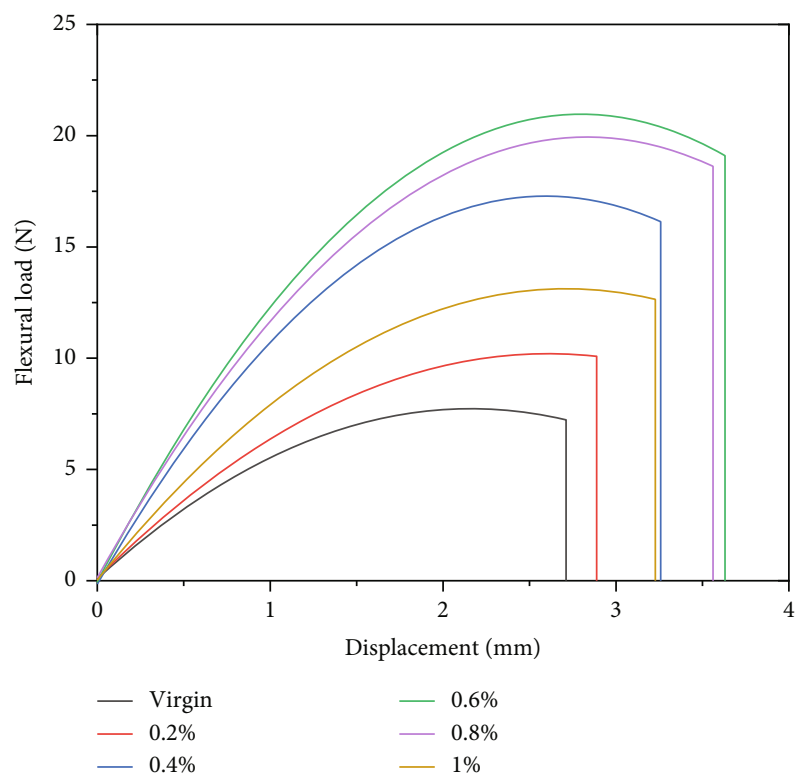

Figure 2: Flexural load vs. displacement of MWCNT nanocomposites.

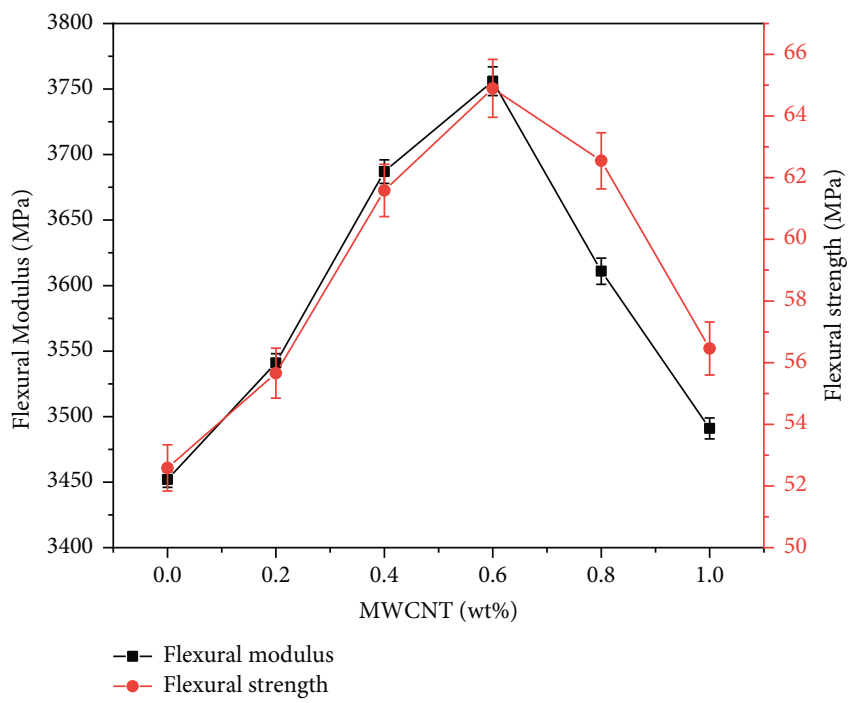

FIGURE 3: Flexural modulus vs. flexural strength of MWCNT nanocomposites.

$0.6 \mathrm{wt} \%$, the flexural load started to decrease. The displacement of polyester with $0.2,0.4,0.6,0.8$, and $1 \mathrm{wt} \%$ of MWCNT reinforcement was increased by $5.9 \%, 16.98 \%$, $24.88 \%, 24.19 \%$, and $15.87 \%$, and flexural load of polyester with same weight concentrations was increased by $31.73 \%$, $55.22 \%, 63.13 \%, 61.10 \%$, and $41.15 \%$, respectively. At $0.6 \mathrm{wt} \%$ of MWCNT reinforcement compared to pure polyester, the maximum enhancement of flexural load and displacement was $63.13 \%$ and $24.88 \%$, respectively. The composite's flexural strength vs. flexural modulus with respect to MWCNT reinforcement is shown in Figure 3. The flexural strength was observed to be enhanced with the increase in MWCNT filler till $0.6 \mathrm{wt} \%$ of reinforcement upto $18.97 \%$ compared to virgin polyester. The same trend was also found

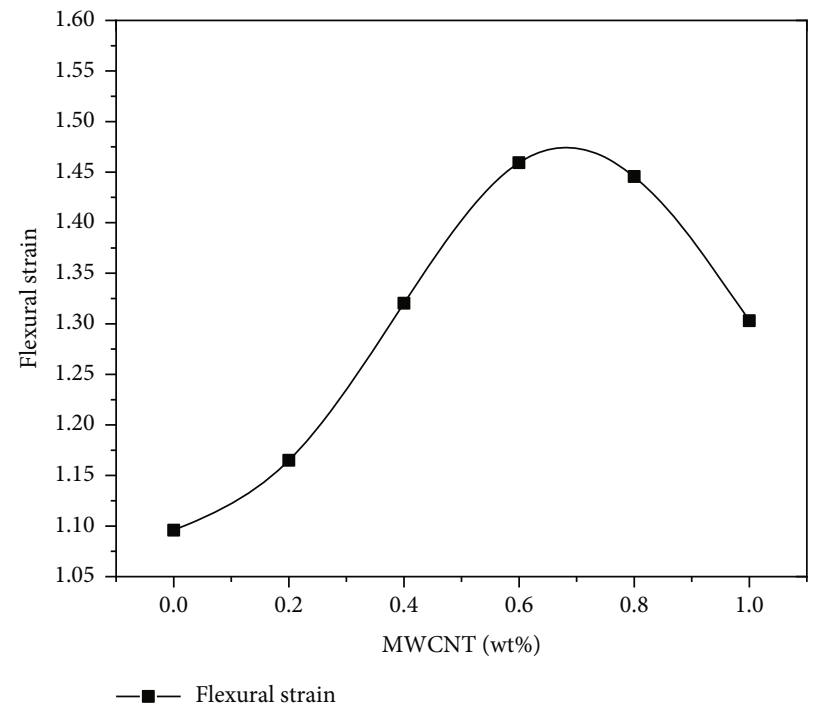

FIGURE 4: Flexural strain of MWCNT nanocomposites.

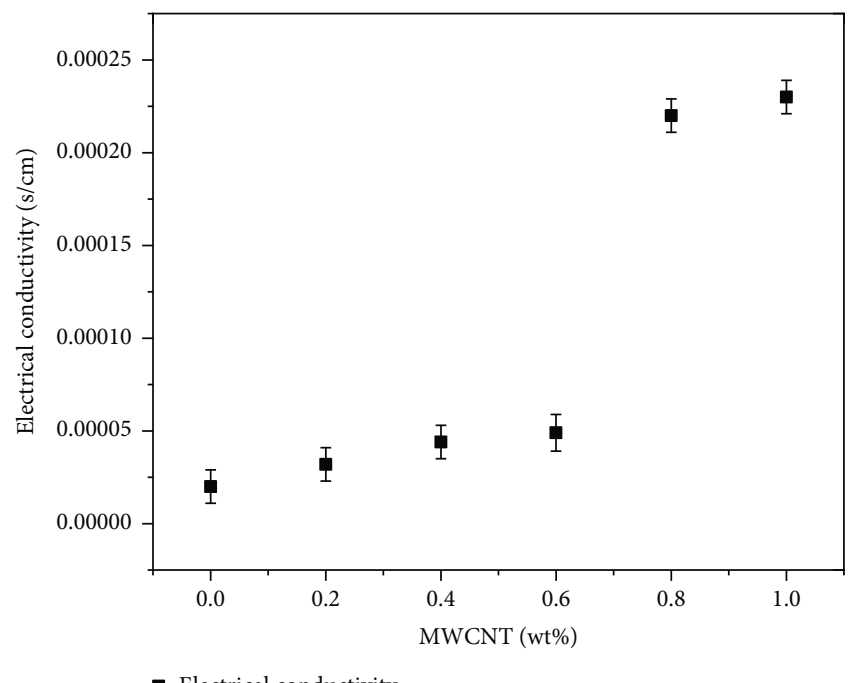

- Electrical conductivity

FIGURE 5: Electrical conductivity of nanocomposites.

in case of flexural modulus. It was noted that the flexural modulus increases by $32.9 \%$ at $0.6 \mathrm{wt} \%$ of reinforcement comparing to the virgin polyester. The maximum enhancement of flexural strain was observed to be $33.02 \%$ for $0.6 \mathrm{wt} \%$ of MWCNT reinforcement as shown in Figure 4.

The reason for the enrichment in mechanical properties up to $0.6 \mathrm{wt} \%$ was the good specific surface area, high aspect ratio, good mechanical properties, and carboxyl modified MWCNT. Also, the homogenous dispersion of nanofiller and a decent interaction of matrix with the reinforcement play a vital role. The mechanical properties of polyester/MWCNT composite were increased by the homogenous dispersion of MWCNT in polyester, which was verified by measuring the electrical conductivity of the composite, and it is shown in Figure 5 [42]. It was observed that the electrical conductivity of $0.8 \mathrm{wt} \% \mathrm{MWCNT}$-reinforced composite rises four times than the electrical conductivity of 0.6 wt\% MWCNT-reinforced composite. Moisala et al. [43] 


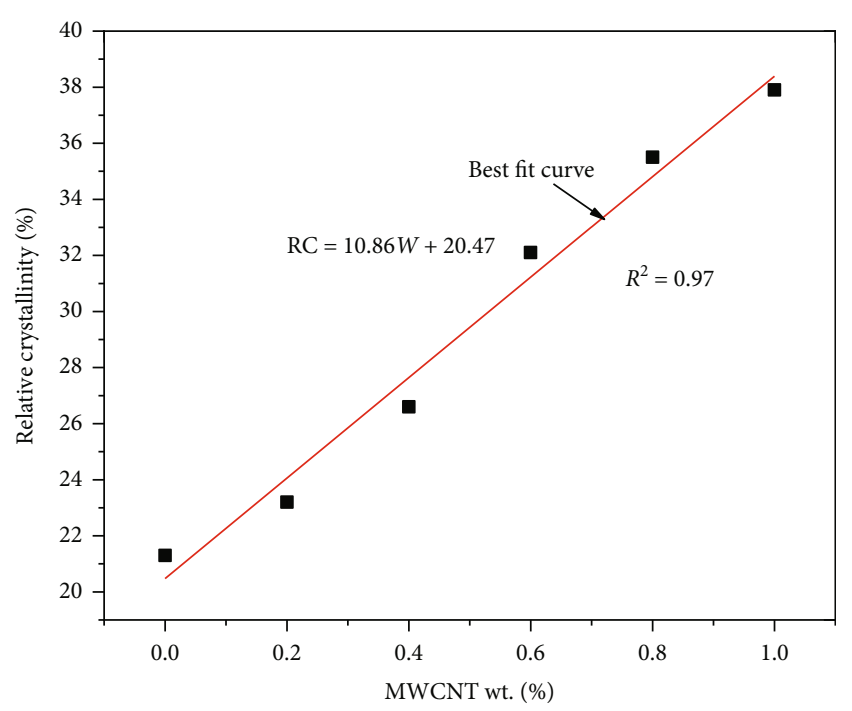

FIgURE 6: Relative crystallinity of MWCNT nanocomposites.

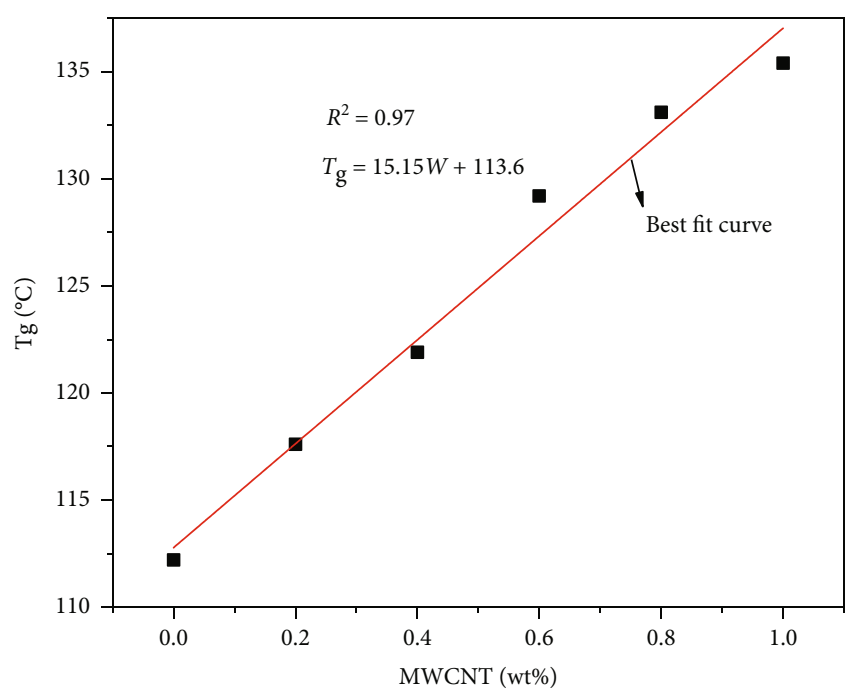

FIGURE 7: Glass transition temperature of nanocomposites.

also stated that with an increase in wt\% of MWCNT in polyester, the resultant polymer's electrical conductivity increases. The uniform dispersion of MWCNT in polyester was further confirmed by lower percolation threshold at $0.6 \mathrm{wt} \%$, where the enhancement was found to be $61.53 \%$ compared to virgin polyester. Abazine et al. [44] also reported that the lower percolation threshold of polyesterMWCNT composite is at $0.6 \mathrm{wt} \%$. Thus, it was noted that mechanical properties of polyester composite were increased till $0.6 \mathrm{wt} \%$ of nanocomposite, and the mechanical properties start to decelerate beyond $0.6 \mathrm{wt} \%$ of MWCNT reinforcement due to agglomeration in composite. Figure 6 shows that the increase in MWCNT composition increases the relative crystallinity of polyester linearly. The relative crystallinity of virgin polyester was perceived as $21.3 \%$, and reinforcing $0.2,0.4,0.6,0.8$, and $1 \mathrm{wt} \%$ of MWCNT increases the relative crystallinity of the composite by $21.35 \%, 24.8 \%, 33.6 \%, 40 \%$, and $43.7 \%$, respectively, as the MWCNT becomes a nucleat-

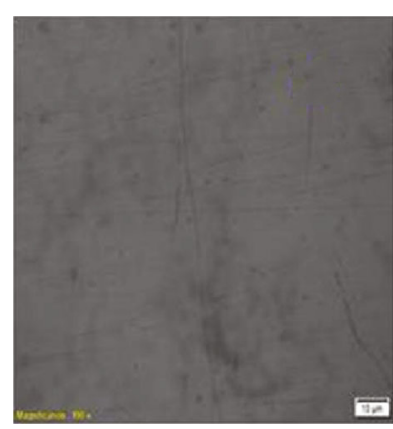

(a)

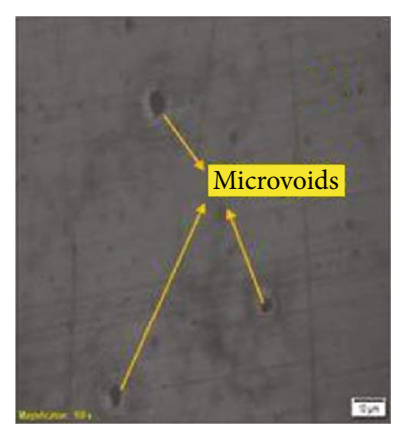

(b)
FIgURE 8: (a) Optical microscope image of $0.6 \mathrm{wt} \%$ PE/MWCNT. (b) Optical microscope image of $1 \mathrm{wt} \% \mathrm{PE} / \mathrm{MWCNT}$.

ing medium by initiating the generation of fresh crystallites. The relative crystallinity graph shows that when MWCNT concentration increases, the rate at which polyester attains relative crystallinity increases. It was observed by Zhang et al. [45] that when relative crystallinity increases, the mechanical properties of polyester with MWCNT increase linearly. Guadagno et al. [46] proved the interfacial catenation of MWCNT using glass transition temperature $\left(T_{\mathrm{g}}\right)$ derivative that accelerates the mechanical properties of polyester composites. Figure 7 depicts that with 0.2, 0.4, 0.6, 0.8, and $1 \mathrm{wt} \%$ of MWCNT reinforcement $T_{\mathrm{g}}$ of composite was increased linearly by $4.5,7.9,13.1,15.7$, and $17.1^{\circ} \mathrm{C}$, respectively. Glass transition temperature of polyester composite increases proportional to the amount of MWCNT reinforced in polyester as MWCNT forms a strong interfacial bonding with composite, and the same has been portrayed by the high linear fitting slope. Thus, it was confirmed that reinforcing MWCNT with polyester enhances its mechanical properties. It was also concluded that $T_{\mathrm{g}}$ and relative crystallinity of polyester increase in proportional to the increase in wt\% of MWCNT in polyester.

The increase in microvoids after $0.6 \mathrm{wt} \%$ of MWCNT might be a probable cause for the declining mechanical property in the composite. Owing to increase in the specific surface area of polyester, the polyester might not be wetting the entire surface area of multiwalled carbon nanotubes, which results in rise of microvoids in the composite [47]. A topography was carried out at 0.6 and $1 \mathrm{wt} \%$ of MWCNTreinforced polyester composites to corroborate the existence of voids in the polyester composites, which is shown in Figure 8 . At $1 \mathrm{wt} \%$ of MWCNT, the microvoids were observed to be grown in number. This increase in microvoids in polyester resin due to MWCNT reinforcement and downgrade the mechanical properties of polyester post $0.6 \mathrm{wt} \%$ of MWCNT reinforcement, and the same has been confirmed by Annala et al. [48]. Complex viscosity of polyester and MWCNT mixture is shown in Figure 9. As MWCNT was added to polyester composite beyond $0.6 \mathrm{wt} \%$, the bond between the MWCNT and polyester increased the complex viscosity which in turn led to microvoid formation, and as the microvoid increased, mechanical properties of the polyester began to decrease. The complex viscosity was $9.5 \%$, $24 \%, 38.7 \%, 45.7 \%$, and $50.6 \%$ when $0.2,0.4,0.6,0.8$, and 


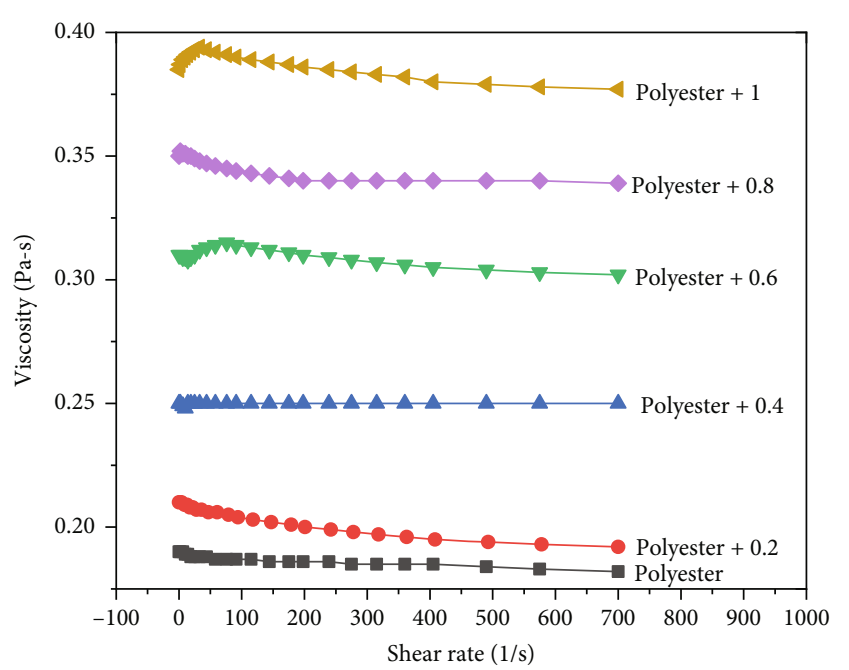

FIGURE 9: Complex viscosity of MWCNT nanocomposites.

$1 \mathrm{wt} \%$ of MWCNT was added with the polyester. Szentes et al. [49] also established the aforementioned results.

3.2. Thermal Properties of Polyester Nanocomposite. Figure 10 depicts the volumetric specific heat of polyester/MWCNT composites against the concentration of MWCNT. The composite's volumetric specific heat decreased when the amount of MWCNT reinforcement in polyester increases. The volumetric specific heat of reinforced composite, with $0.2,0.4$, $0.6,0.8$, and $1 \mathrm{wt} \%$ of MWCNT, was observed to be reduced by $7.8 \%, 13.4 \%, 26.8 \%, 35.4 \%$, and $37.9 \%$ comparing to unreinforced polyester, respectively. Thus, the heat build-up in residual stump was expected to lessen as the volumetric specific heat falls with addition of MWCNT, making it an ideal material for sockets. Figure 11 shows that the thermal diffusivity of the polyester increases with increase in the wt $\%$ of MWCNT added to composite. The thermal diffusivity was enhanced by $17.6 \%, 30.1 \%, 47.7 \%, 57.5 \%$, and $62.6 \%$ with respect to virgin polyester by reinforcing $0.2,0.4,0.6,0.8$, and $1 \mathrm{wt} \%$ of MWCNT, respectively. The 0.6 and $1 \mathrm{wt} \%$ of polyester/MWCNT composite was noted to have $5.34 \times$ $10^{-5} \pm 2.5 \times 10^{-6}$ and $7.48 \times 10^{-5} \pm 2.5 \times 10^{-6} \mathrm{~m}^{2} / \mathrm{s}$ thermal diffusivity, respectively, whereas the thermal diffusivity of pure polyester is $2.79 \times 10^{-5} \pm 4.8 \times 10^{-5} \mathrm{~m}^{2} / \mathrm{s}$. Thus, as polyester's thermal diffusivity increases with addition of MWCNT, the rate at which heat was diffused via socket from stump was boosted. The thermal conductivity of polyester with MWCNT reinforcement is shown in Figure 11. It was noticed, as the concentration of MWCNT increases, the thermal conductivity of polyester also increased proportionally. In comparison with virgin polyester, the thermal conductivity of $0.2,0.4,0.6,0.8$, and $1 \mathrm{wt} \%$ of MWCNT-reinforced composite increased by $8.47 \%, 19.40 \%, 30.76 \%, 41.30 \%$, and $95.68 \%$, respectively.

The thermal diffusivity, thermal conductivity, and volumetric specific heat of polyester and MWCNT were shown in Table 1, where the values for polyester were acquired through experiment, and the value for MWCNT was taken from Yang et al. [50]. It is concluded that the MWCNT has

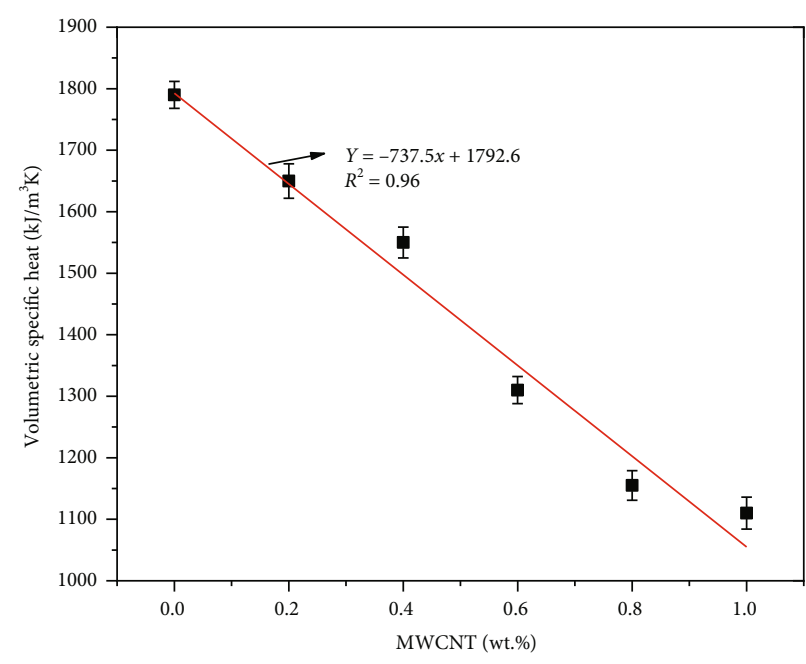

FIGURE 10: Volumetric specific heat of MWCNT nanocomposites.

high thermal conductivity compared to unreinforced polyester, which leads to the increase in the thermal conductivity of polyester composite. The unreinforced polyester has high volumetric specific heat comparing to MWCNT. The thermal diffusivity of MWCNT is 2 times more than the thermal diffusivity of the unreinforced polyester. Hence, reinforcing MWCNT with polyester increases thermal diffusivity, decreases the volumetric specific heat, and also increases the thermal conductivity of polyester composite.

The relative crystallinity shows that with increase of MWCNT wt\% in polyester, the number of geometrically regular crystals increases in the polyester. The enhancement in the number of geometrically regular crystals increases the conduction between the elements of the composite. The thermal conductivity of the composite increases due to the crystalline structure in packing of polymer by lowering the thermal boundary resistance. The enhanced degree of structural order leads to thermal equilibrium early than the virgin polyester which decreases the volumetric specific heat and increases the thermal diffusivity of the polyester nanocomposite. The increase in relative crystallinity against the increase in MWCNT concentration in composite is shown in Figure 7. The aforementioned analysis was supported by Zhang et al. [45]. Glass transition temperature enhancement portrays the bonding of polyester and MWCNT, which is shown in Figure 9. A better interaction between the elements of the composite lead to less thermal boundary resistance among the elements, and the resultant composite has enhanced thermal diffusivity and thermal conductivity and less volumetric specific heat.

Hence, reinforcing MWCNT with polyester would enhance the thermal property of polyester composites. Zhou et al. [26] described that enhancing the thermal stability increases the thermal properties of the polyester nanocomposite. The above discussion confirmed that the thermal conductivity and thermal diffusivity of the polyester composite increases when reinforced with MWCNT and volumetric specific heat decreases. However, after $0.6 \mathrm{wt} \%$ of nanocomposite reinforcement, it is noted that the composite's 


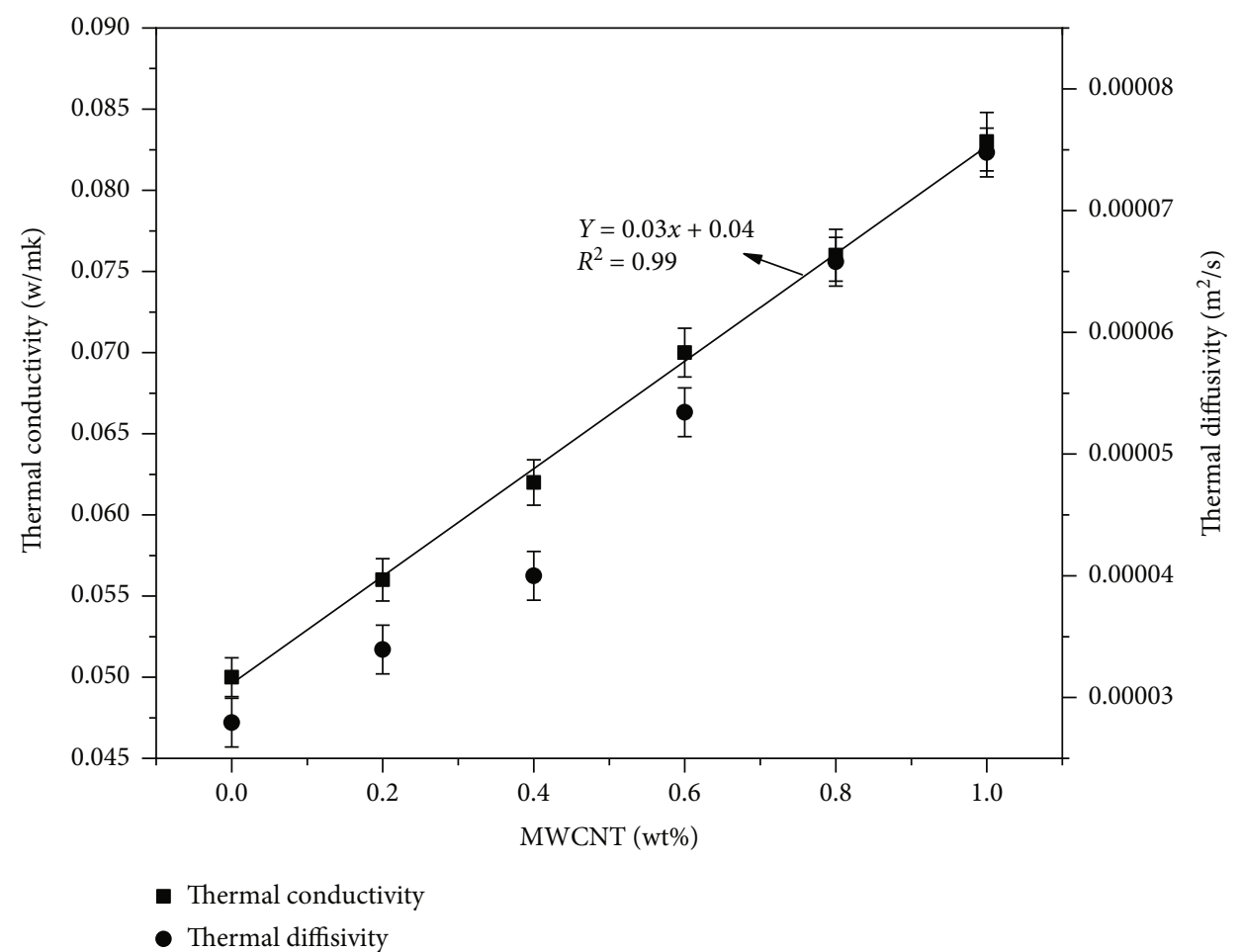

FIGURE 11: MWCNT-reinforced composite's thermal diffusivity and thermal conductivity.

TABLe 1: Thermal properties.

\begin{tabular}{lccc}
\hline Thermal properties & Thermal conductivity $(\mathrm{W} / \mathrm{mK})$ & Thermal diffusivity $\left(\mathrm{m}^{2} / \mathrm{s}\right)$ & Volumetric specific heat $\left(\mathrm{kJ} / \mathrm{m}^{3} \mathrm{k}\right)$ \\
\hline MWCNT, Yang et al. [50] & 3000 & $4.3 \times 10^{-3}$ & 700 \\
Polyester & $0.05 \pm 0.0058$ & $2.79 \times 10^{-5} \pm 2.8 \times 10^{-6}$ & $1790 \times 18$ \\
\hline
\end{tabular}

mechanical properties decrease. Thus, to prepare sandwichstructured composite for prosthetic sockets, $0.6 \mathrm{wt} \%$ of MWCNT can be considered.

\subsection{Characterization of Sandwich-Structured Nanocomposites.} PE/MWCNT composite was optimized to yield better mechanical and thermal properties. PE/fiberglass cloth/stockinette layers (0-10 layers) sandwich-structured composite was prepared with and without reinforcing $0.6 \mathrm{wt} \%$ of MWCNT. $200 \times 200 \mathrm{~mm}$ rectangular sheet of composite was considered for measuring the weight of composite. The weight of the composite increased by $80 \%, 162 \%, 208 \%, 296 \%$, and $393 \%$ for $2,4,6,8$, and 10 stockinette layers of composite, respectively, compared with the composite without stockinette layer, and the same was depicted in Figure 12. Smith and Martin [7] stated that the metabolic cost increases by $12 \%$, when the weight variation between the prosthetic leg and the other leg of an amputee is $100 \%$. Thus, by reducing the number of stockinette layers, the weight of the socket could be reduced, which in turn will reduce the metabolic cost of amputee.

3.4. Thermal Properties of Sandwich-Structured Nanocomposites. The variation in thermal properties of $0.6 \mathrm{wt} \%$ MWCNT-reinforced composites was discussed in this section. It was observed that the thermal conductivity increased by $2.9 \%$ for $2-10$ stockinette layers of sandwichstructured composite by reinforcing $0.6 \mathrm{wt} \%$ MWCNT compared to unreinforced composite. Figure 13 depicts the thermal properties of the various forms of polyester composites. The sandwich-structured composite with $0.6 \mathrm{wt} \%$ reinforced MWCNT has $19.4 \%$ less volumetric specific heat than the virgin polyester. This less volumetric specific heat helps in decreasing the socket temperature with less available heat in the socket. The energy required to increase the temperature of polyester/fiberglass, sandwich-structured composite, and sandwich-structured composite reinforced with $0.6 \mathrm{wt} \%$ MWCNT is $18.2 \%, 25.4 \%$, and $38.5 \%$ less than the energy desired for socket made of unreinforced polyester, respectively. Mak et al. [6] stated that the $1^{\circ} \mathrm{C}$ rise in temperature within the socket leads to $10 \%$ hike in metabolic cost.

The increase in thermal diffusivity and thermal conductivity and decrease of volumetric specific heat of polyester based on different types of composites with respect to polyester are shown in Figure 13. It was noticed that the increase in thermal diffusivity for polyester/fiberglass, sandwichstructured, and $0.6 \mathrm{wt} \%$ sandwich-structured reinforced nanocomposites is $138 \%, 176.5 \%$, and $315.7 \%$, respectively, comparing to virgin polyester, and the thermal conductivity was noted to be enhanced by $15.2 \%, 25.7 \%$, and $68.4 \%$, respectively, and the volumetric specific heat of the composites was 


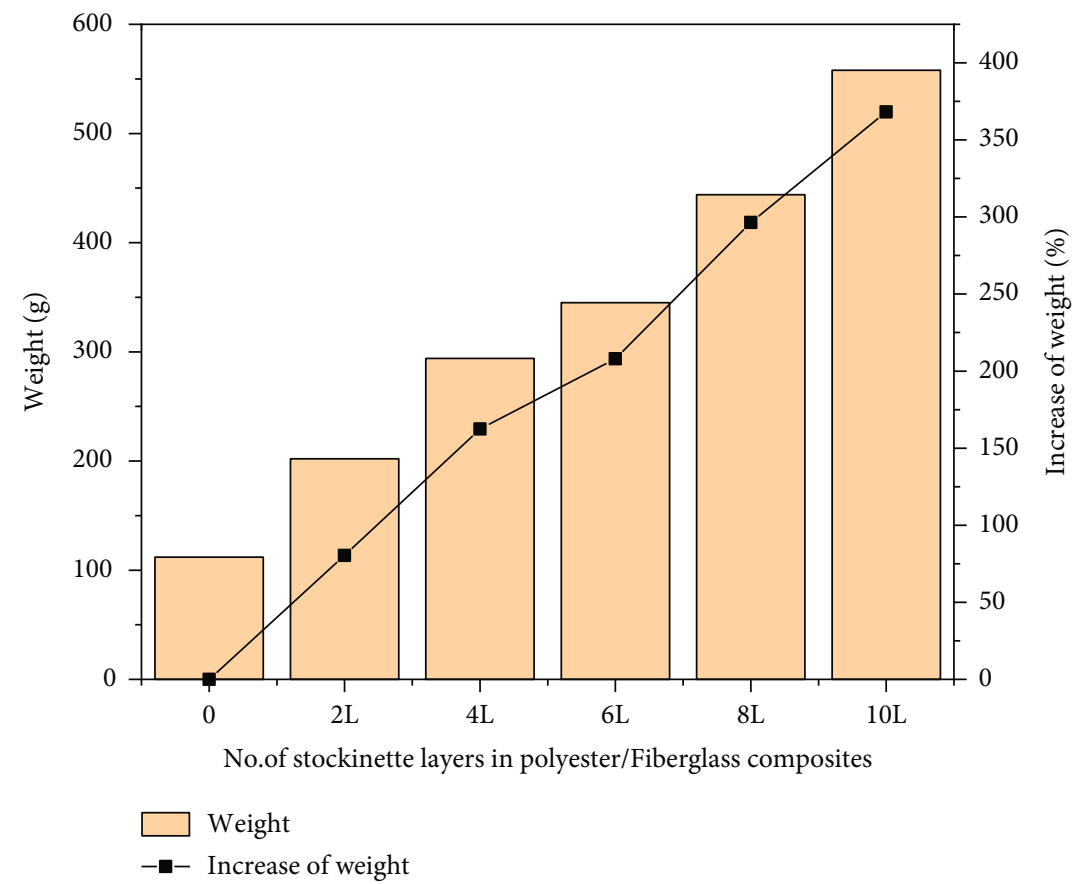

FIGURE 12: Weight of polyester/fiberglass composites with various stockinette structure and weight of composites without stockinette structure layers.

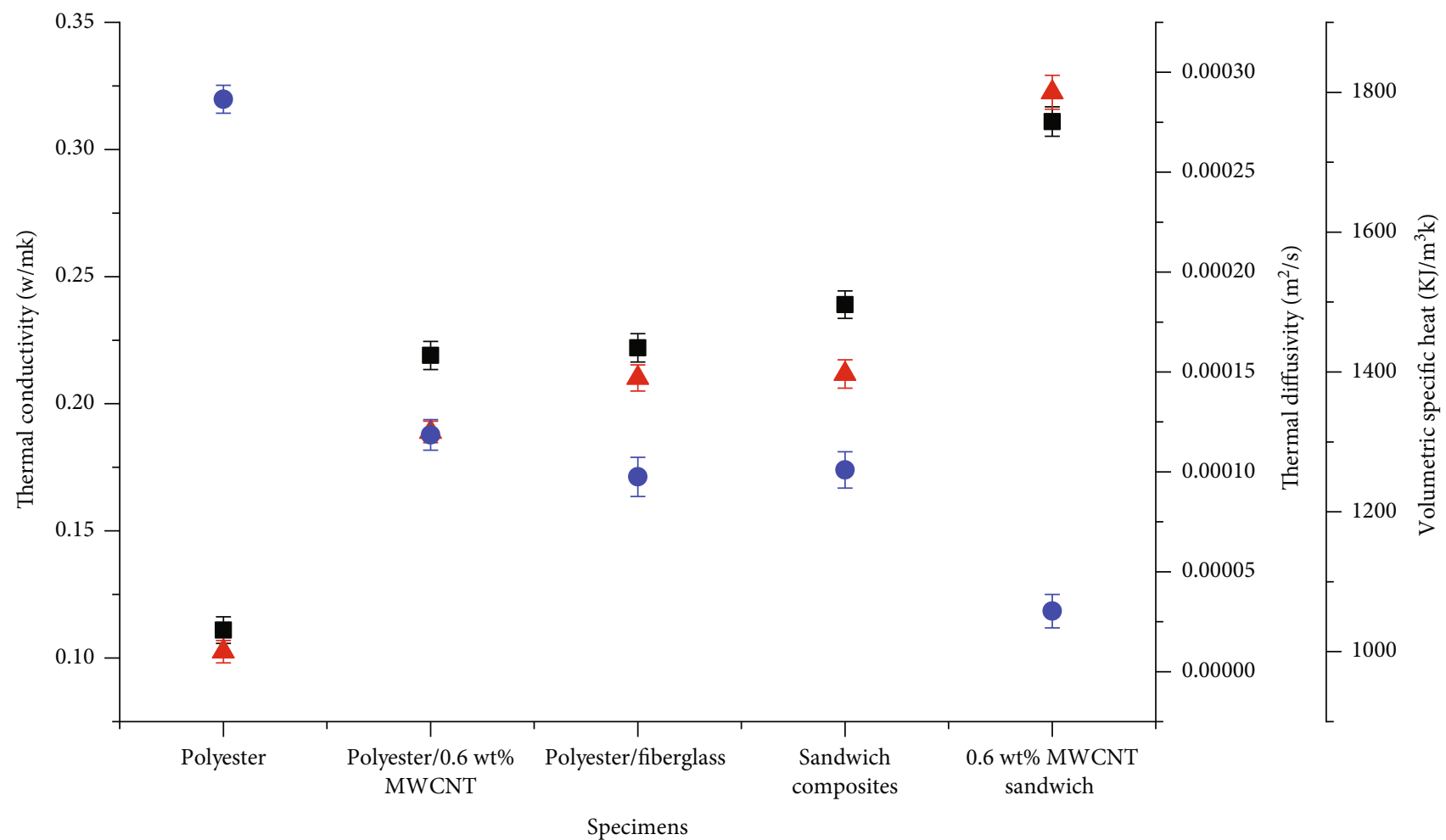

- Thermal conductivity $(\mathrm{w} / \mathrm{mk})$

Thermal diffusivity $\left(\mathrm{m}^{2} / \mathrm{s}\right)$

Volumetric specific heat $\left(\mathrm{KJ} / \mathrm{m}^{3} \mathrm{k}\right)$

FiguRE 13: Thermal properties of polyester based various forms of composites. 


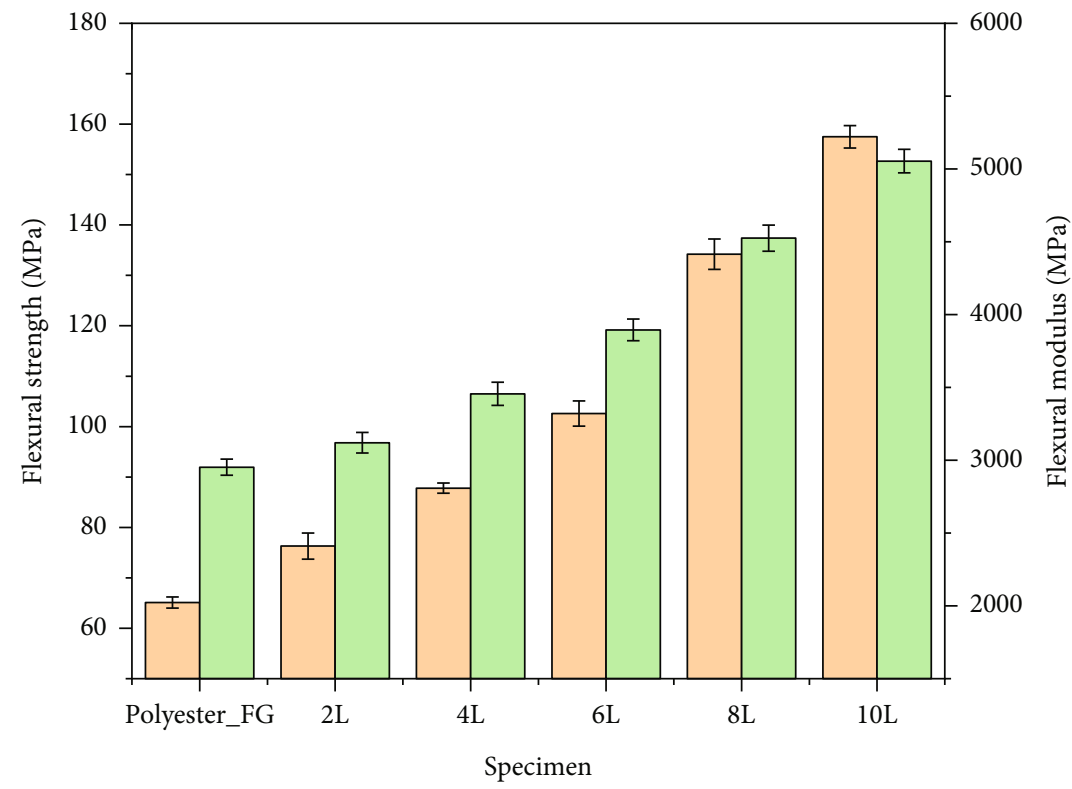

\section{Flexural strength}

Flexural modulus

FIGURE 14: Sandwich-structured composite’s flexural strength and flexural modulus.

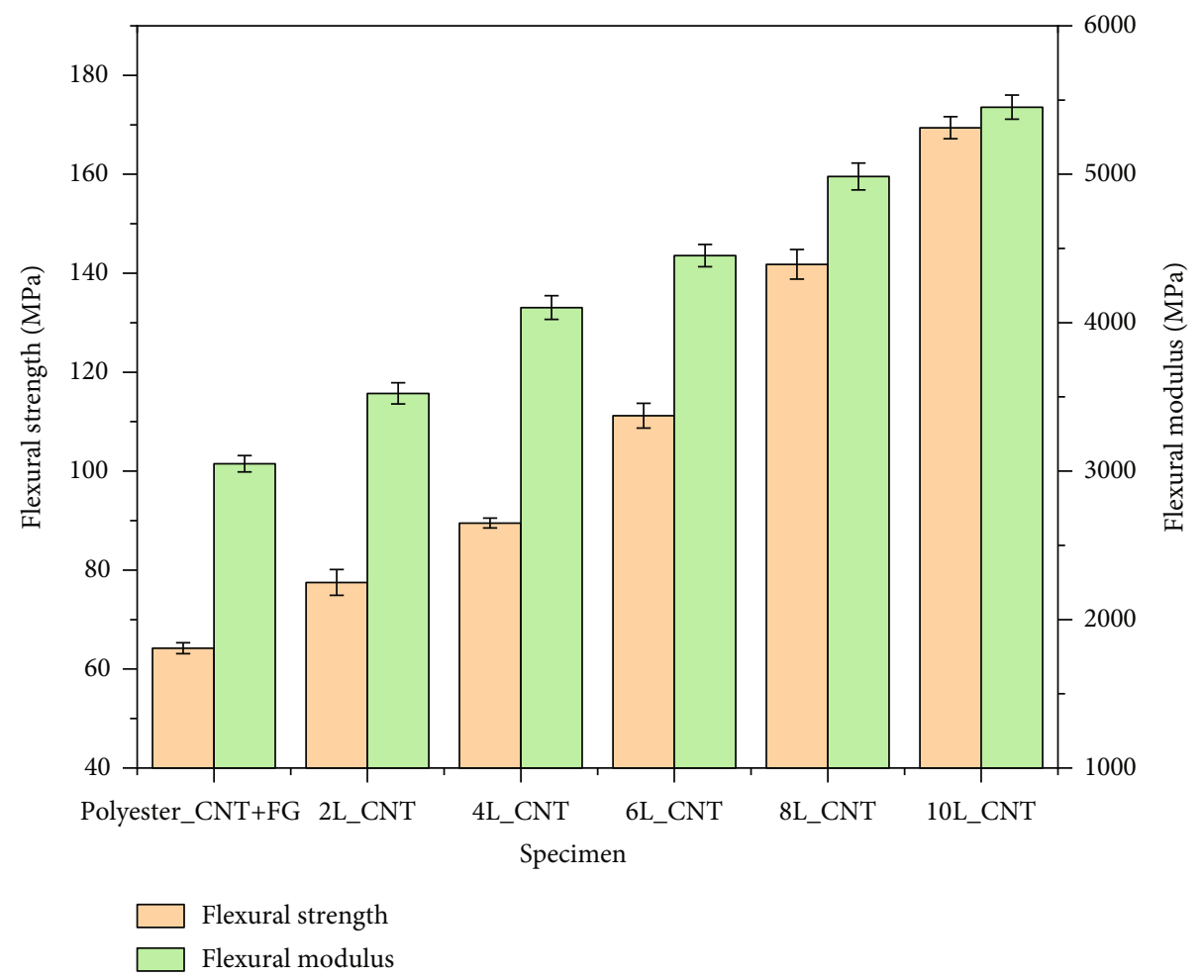

FIGURE 15: MWCNT reinforced with sandwich-structured composite's flexural strength and flexural modulus.

decreased by $31.8 \%, 40.7 \%$, and $53.8 \%$, respectively. The rate of heat diffusion from socket to its environment was expected to increase as the MWCNT-reinforced polyester composite has higher thermal diffusivity. It was also noted that the thermal diffusivity and conductivity of sandwich-structured composites with $0.6 \mathrm{wt} \%$ MWCNT reinforced were im- proved by $40.8 \%$ and $25.7 \%$, respectively, compared to sandwich-structured composites without MWCNT. Thus, by using MWCNT-reinforced sandwich-structured composite, the heat accumulation in socket will be reduced to a great extent, and the heat is transferred to enhance the quality of life and lower the metabolic cost of the amputee. 
3.5. Mechanical Properties of Sandwich-Structured Nanocomposites. Figures 14 and 15 depict the flexural modulus and flexural strength of unreinforced polyester sandwichstructured composite and $0.6 \mathrm{wt} \%$ MWCNT-reinforced sandwich-structured composite, respectively. It was noted that with increase in number of stockinette layers in polyester/fiberglass composite, the flexural property of the composite increases. It was further observed that when $0.6 \mathrm{wt} \%$ MWCNT is reinforced in the polyester composite, the composite's flexural property increases even further. The flexural strength of $0.6 \mathrm{wt} \%$ MWCNT-reinforced polyester composite with $2-10$ stockinette layers, increases by $11 \pm 1.4 \%$ compared to unreinforced sandwich-structured composite. It was also observed that the flexural modulus of polyester composite reinforced with $0.6 \mathrm{wt} \% \mathrm{MWCNT}$ for 2-10 stockinette layers increases by $9.4 \pm 1.3 \%$, while compared to the polyester composite without MWCNT reinforcement. The reason for increase in the flexural property of the MWCNTreinforced sandwich-structured and the reason for strong bonding between stockinette layer, polyester, and MWCNT were discussed earlier.

Thermal diffusivity, thermal conductivity, and volumetric specific heat enhance transfemoral socket's heat transfer characteristics, which in turn leads to less heat accumulation in the socket. It was noted that the enhancement in mechanical properties due to $0.6 \mathrm{wt} \%$ MWCNT reinforcement in sandwich-structured allows to reduce two stockinette layers, i.e., instead of 8 stockinette layers, the desired properties can be obtained from 6 stockinette layers based on amputees current requirement. This in turn reduces the total weight of the socket which leads to less metabolic cost of the amputee.

\section{Conclusion}

In summary, $0.2,0.4,0.6,0.8$, and $1 \mathrm{wt} \%$ chemically treated MWCNT was reinforced with polyester resin to prepare the composite. Vacuum drying and solution dispersion technique was used to prepare the composite. The flexural strength, flexural modulus, flexural strain, thermal conductivity, and thermal diffusivity increased up to $18.97 \%, 32.9 \%$, $33.02 \%, 30.7 \%$, and $47.7 \%$, respectively, and volumetric specific heat decreased by $26.8 \%$ for $0.6 \mathrm{wt} \%$ MWCNTreinforced composite. The trend of results shows that addition of MWCNT at low weight fractions improves mechanical properties of polyester resin. The root cause for the increment of thermal and mechanical properties with MWCNT reinforcement and the depletion of mechanical properties after $0.6 \mathrm{wt} \%$ of MWCNT were explored thoroughly. The flexural strength of $0.6 \mathrm{wt} \%$ MWCNT-reinforced polyester composite with 4-10 stockinette layers was $11.4 \%$ higher than the unreinforced polyester composite. The thermal conductivity increases by $68.4 \%$ and thermal diffusivity increases by $315.7 \%$, for MWCNT-reinforced sandwich composite while compared to unreinforced sandwich composite. The increase in mechanical properties with $0.6 \mathrm{wt} \%$ MWCNT reinforcements allows to reduce 2 stockinette layers that results in less socket weight. The mechanical properties and heat transfer characteristic of the polyester/fiberglass cloth/stockinette sandwich-structured composite were enhanced to a notable amount. The collaborative result of the same and less weight of the socket should be helpful for making a socket with less metabolic cost for a transfemoral amputee.

\section{Data Availability}

The data used to support the findings of this study are available from the corresponding author upon request.

\section{Conflicts of Interest}

The authors declare that they have no conflicts of interest.

\section{Acknowledgments}

The authors would like to thank Sathyabama Institute of Science and Technology Chennai for using the laboratory facility of the Centre for Nanoscience and Nanotechnology.

\section{References}

[1] D. Lacroix and J. F. Ramírez Patiño, "Finite element analysis of donning procedure of a prosthetic transfemoral socket," Annals of Biomedical Engineering, vol. 39, no. 12, pp. 29722983, 2011.

[2] P. Varma, M. G. Stineman, and T. R. Dillingham, "Epidemiology of limb loss," Physical Medicine and Rehabilitation Clinics of North America, vol. 25, no. 1, pp. 1-8, 2014.

[3] S. Portnoy, G. Yarnitzky, Z. Yizhar et al., "Real-time patientspecific finite element analysis of internal stresses in the soft tissues of a residual limb: a new tool for prosthetic fitting," Annals of Biomedical Engineering, vol. 35, no. 1, pp. 120-135, 2006.

[4] J. Cochrane, A Rehabilitation of Stochastic Discount Factor Methodology, National Bureau of Economic Research, Cambridge, MA, USA, 2001.

[5] G. K. Klute, G. I. Rowe, A. V. Mamishev, and W. R. Ledoux, "The thermal conductivity of prosthetic sockets and liners," Prosthetics and Orthotics International, vol. 31, no. 3, pp. 292-299, 2016.

[6] M. AFT, M. Zhang, and D. A. Boone, "State-of-the-art research in lower-limb prosthetic biomechanics- socket interface: a review," Journal of Rehabilitation Research and Development, vol. 38, no. 2, 2001.

[7] J. D. Smith and P. E. Martin, "Effects of prosthetic mass distribution on metabolic costs and walking symmetry," Journal of Applied Biomechanics, vol. 29, no. 3, pp. 317-328, 2013.

[8] R. S. Gailey, D. Lawrence, C. Burditt, P. Spyropoulos, C. Newell, and M. S. Nash, "The CAT-CAM socket and quadrilateral socket: a comparison of energy cost during ambulation," Prosthetics and Orthotics International, vol. 17, no. 2, pp. 95-100, 1993.

[9] E. E. Ureña-Benavides, M. J. Kayatin, and V. A. Davis, "Dispersion and rheology of multiwalled carbon nanotubes in unsaturated polyester resin," Macromolecules, vol. 46, no. 4, pp. 1642-1650, 2013.

[10] R. H. Baughman, A. A. Zakhidov, and W. A. de Heer, "Carbon nanotubes-the route toward applications," Science, vol. 297, no. 5582, pp. 787-792, 2002. 
[11] A. Allaoui, "Mechanical and electrical properties of a MWNT/epoxy composite," Composites Science and Technology, vol. 62, no. 15, pp. 1993-1998, 2002.

[12] A. Battisti, A. A. Skordos, and I. K. Partridge, "Monitoring dispersion of carbon nanotubes in a thermosetting polyester resin," Composites Science and Technology, vol. 69, no. 10, pp. 1516-1520, 2009.

[13] S. Khostavan, M. Fazli, M. G. Ahangari, and Y. Rostamiyan, "The effect of interaction between nanofillers and epoxy on mechanical and thermal properties of nanocomposites: theoretical prediction and experimental analysis," Advances in Polymer Technology, vol. 2019, Article ID 8156718, 10 pages, 2019.

[14] F. Anjum, N. Gull, S. M. Khan et al., "Mechanical, thermal, and microscopic profile of novel glass fiber-reinforced polyester composites as a function of barium sulfate loading," Advances in Polymer Technology, vol. 37, no. 3, 2018.

[15] N. Gull, et al.S. M. Khan, M. A. Munawar et al., "Synthesis and characterization of zinc oxide $(\mathrm{ZnO})$ filled glass fiber reinforced polyester composites," Materials \& Design, vol. 67, pp. 313-317, 2015.

[16] M. D. H. Beg, A. K. M. M. Alam, R. M. Yunus, and M. F. Mina, "Improvement of interaction between pre-dispersed multiwalled carbon nanotubes and unsaturated polyester resin," Journal of Nanoparticle Research, vol. 17, no. 1, 2015.

[17] J. N. Coleman, U. Khan, W. J. Blau, and Y. K. Gun'ko, “Small but strong: a review of the mechanical properties of carbon nanotube-polymer composites," Carbon, vol. 44, no. 9, pp. 1624-1652, 2006.

[18] M. S. I. Makki, M. Y. Abdelaal, S. Bellucci, and M. Abdel Salam, "Multi-walled carbon nanotubes/unsaturated polyester composites: mechanical and thermal properties study," Fullerenes, Nanotubes, and Carbon Nanostructures, vol. 22, no. 9, pp. 820-833, 2014.

[19] N.-H. Tai, M.-K. Yeh, and T.-H. Peng, "Experimental study and theoretical analysis on the mechanical properties of SWNTs/phenolic composites," Composites Part B: Engineering, vol. 39, no. 6, pp. 926-932, 2008.

[20] J. Vera-Agullo, A. Glória-Pereira, H. Varela-Rizo, J. L. Gonzalez, and I. Martin-Gullon, "Comparative study of the dispersion and functional properties of multiwall carbon nanotubes and helical-ribbon carbon nanofibers in polyester nanocomposites," Composites Science and Technology, vol. 69, no. 10, pp. 15211532, 2009.

[21] M.-Y. Yen, M.-C. Hsiao, S.-H. Liao et al., "Preparation of graphene/multi-walled carbon nanotube hybrid and its use as photoanodes of dye-sensitized solar cells," Carbon, vol. 49, no. 11, pp. 3597-3606, 2011.

[22] M. A. Munawar, S. M. Khan, N. Gull et al., "Fabrication and characterization of novel zirconia filled glass fiber reinforced polyester hybrid composites," Journal of Applied Polymer Science, vol. 133, no. 27, 2016.

[23] K. C. Etika, L. Liu, L. A. Hess, and J. C. Grunlan, "The influence of synergistic stabilization of carbon black and clay on the electrical and mechanical properties of epoxy composites," Carbon, vol. 47, no. 13, pp. 3128-3136, 2009.

[24] A. T. Seyhan, F. H. Gojny, M. Tanoğlu, and K. Schulte, "Critical aspects related to processing of carbon nanotube/unsaturated thermoset polyester nanocomposites," European Polymer Journal, vol. 43, no. 2, pp. 374-379, 2007.

[25] E. Borowski, E. Soliman, U. Kandil, and M. Taha, "Interlaminar fracture toughness of CFRP laminates incorporating multi-walled carbon nanotubes," Polymers, vol. 7, no. 6 , pp. 1020-1045, 2015.

[26] T. Zhou, X. Wang, and T. Wang, "Cure reaction of multi-walled carbon nanotubes/diglycidyl ether of bisphenol A/2-ethyl-4methylimidazole (MWCNTs/DGEBA/EMI-2,4) nanocomposites: effect of carboxylic functionalization of MWCNTs," Polymer International, vol. 58, no. 4, pp. 445-452, 2009.

[27] S. Arun and S. Kanagaraj, "Performance enhancement of epoxy based sandwich composites using multiwalled carbon nanotubes for the application of sockets in trans-femoral amputees," Journal of the Mechanical Behavior of Biomedical Materials, vol. 59, pp. 1-10, 2016.

[28] V.-T. Hoang and Y.-J. Yum, "Optimization of the fabrication conditions and effects of multi-walled carbon nanotubes on the tensile properties of various glass fibers/unsaturated polyester resin composites," e-Polymers, vol. 18, no. 5, pp. 441451, 2018.

[29] F. Vahedi, H. R. Shahverdi, M. M. Shokrieh, and M. Esmkhani, "Effects of carbon nanotube content on the mechanical and electrical properties of epoxy-based composites," New Carbon Materials, vol. 29, no. 6, pp. 419-425, 2014.

[30] M. M. Shokrieh, A. Saeedi, and M. Chitsazzadeh, "Mechanical properties of multi-walled carbon nanotube/polyester nanocomposites," Journal of Nanostructure in Chemistry, vol. 3, no. $1,2013$.

[31] F. Gojny, M. Wichmann, B. Fiedler, and K. Schulte, "Influence of different carbon nanotubes on the mechanical properties of epoxy matrix composites - a comparative study," Composites Science and Technology, vol. 65, no. 15-16, pp. 2300-2313, 2005.

[32] O. Starkova, S. T. Buschhorn, E. Mannov, K. Schulte, and A. Aniskevich, "Creep and recovery of epoxy/MWCNT nanocomposites," Composites Part A: Applied Science and Manufacturing, vol. 43, no. 8, pp. 1212-1218, 2012.

[33] J. G. Park, Q. Cheng, J. Lu et al., “Thermal conductivity of MWCNT/epoxy composites: the effects of length, alignment and functionalization," Carbon, vol. 50, no. 6, pp. 2083-2090, 2012.

[34] J.-M. Park, P.-G. Kim, J.-H. Jang et al., "Self-sensing and dispersive evaluation of single carbon fiber/carbon nanotube (CNT)-epoxy composites using electro-micromechanical technique and nondestructive acoustic emission," Composites Part B: Engineering, vol. 39, no. 7-8, pp. 1170-1182, 2008.

[35] S. Ojha, S. Acharya, and G. Raghavendra, "A novel approach to utilize waste carbon as reinforcement in thermoset composite," Proceedings of the Institution of Mechanical Engineers, Part E: Journal of Process Mechanical Engineering, vol. 230, no. 4, pp. 263-273, 2014.

[36] Y. Rachmadini, V. B. C. Tan, and T. E. Tay, "Enhancement of mechanical properties of composites through incorporation of CNT in VARTM - a review," Journal of Reinforced Plastics and Composites, vol. 29, no. 18, pp. 2782-2807, 2010.

[37] A. F. Ireana Yusra, H. P. S. Abdul Khalil, M. S. Hossain et al., "Characterization of plant nanofiber-reinforced epoxy composites," BioResources, vol. 10, no. 4, 2015.

[38] C. M. Damian, A. M. Pandele, C. Andronescu, A. Ghebaur, S. A. Garea, and H. Iovu, "Epoxy-based nanocomposites reinforced with new amino functionalized multi-walled carbon nanotubes," Fullerenes, Nanotubes, and Carbon Nanostructures, vol. 19, no. 3, pp. 197-209, 2011.

[39] S. Barrau, P. Demont, A. Peigney, C. Laurent, and C. Lacabanne, "DC and AC conductivity of carbon nanotubes-polyepoxy 
composites," Macromolecules, vol. 36, no. 14, pp. 5187-5194, 2003.

[40] S.-M. Yuen, C.-C. M. Ma, H.-H. Wu et al., "Preparation and thermal, electrical, and morphological properties of multiwalled carbon nanotubeand epoxy composites," Journal of Applied Polymer Science, vol. 103, no. 2, pp. 1272-1278, 2007.

[41] M. Theodore, M. Hosur, J. Thomas, and S. Jeelani, "Influence of functionalization on properties of MWCNT-epoxy nanocomposites," Materials Science and Engineering: A, vol. 528, no. 3, pp. 1192-1200, 2011

[42] S. Arun and S. Kanagaraj, "Mechanical characterization and validation of poly (methyl methacrylate)/multi walled carbon nanotube composite for the polycentric knee joint," Journal of the Mechanical Behavior of Biomedical Materials, vol. 50, pp. 33-42, 2015.

[43] A. Moisala, Q. Li, I. A. Kinloch, and A. H. Windle, "Thermal and electrical conductivity of single- and multi-walled carbon nanotube-epoxy composites," Composites Science and Technology, vol. 66, no. 10, pp. 1285-1288, 2006.

[44] K. Abazine, H. Anakiou, M. El Hasnaoui et al., "Electrical conductivity of multiwalled carbon nanotubes/polyester polymer nanocomposites," Journal of Composite Materials, vol. 50, no. 23, pp. 3283-3290, 2016.

[45] S. Zhang, M. L. Minus, L. Zhu, C.-P. Wong, and S. Kumar, "Polymer transcrystallinity induced by carbon nanotubes," Polymer, vol. 49, no. 5, pp. 1356-1364, 2008.

[46] L. Guadagno, L. Vertuccio, A. Sorrentino et al., "Mechanical and barrier properties of epoxy resin filled with multi-walled carbon nanotubes," Carbon, vol. 47, no. 10, pp. 2419-2430, 2009.

[47] K. K. Panchagnula and P. Kuppan, "Improvement in the mechanical properties of neat GFRPs with multi-walled CNTs," Journal of Materials Research and Technology, vol. 8, no. 1, pp. 366-376, 2019.

[48] M. Annala, M. Lahelin, and J. Seppala, "Utilization of poly (methyl methacrylate) - carbon nanotube and polystyrene carbon nanotube in situ polymerized composites as masterbatches for melt mixing," Express Polymer Letters, vol. 6, no. 10, pp. 814-825, 2012.

[49] A. Szentes, C. Varga, G. Horvath et al., "Electrical resistivity and thermal properties of compatibilized multi-walled carbon nanotube/polypropylene composites," Express Polymer Letters, vol. 6, no. 6, pp. 494-502, 2012.

[50] K. Yang, M. Gu, Y. Guo, X. Pan, and G. Mu, "Effects of carbon nanotube functionalization on the mechanical and thermal properties of epoxy composites," Carbon, vol. 47, no. 7, pp. 1723-1737, 2009. 